
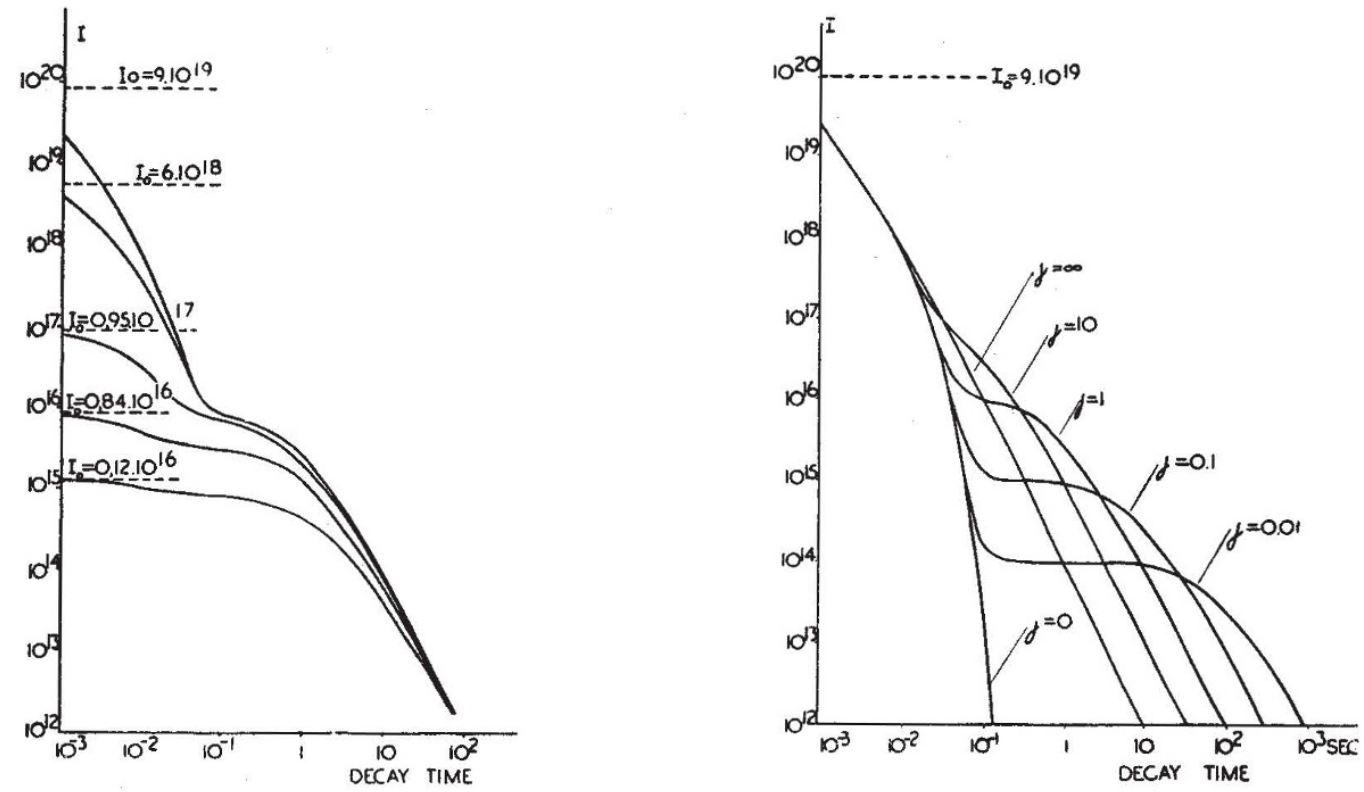

THEORETICAL DECAY CURVES FOR DIFFERENT VALUES OF THE INITIAL INTENSITY AND FOR DIFFERENT TEMPERATURES

$I^{\prime}$ is strongly temperature-dependent and may be called phosphorescence in agreement with a suggestion put forward by Pringsheim. $I_{0}^{\prime}$ is then the phosphorescence intensity extrapolated to $t=0$. $r$ decreases during the decay to its asymptotic value $R$. At very densities of excitation $\boldsymbol{r}_{0}$ may be equal to $R$. The decay then tion $r$, to one bimolecular curve. With increasing densities of excitaThe phosphorescence is then saturated.

At very low temperatures $I_{0}^{\prime}=0$. All traps are filled during excitation and the phosphorescence is then frozen in. The decay is bimolecular initially if $L \ll n$ but always changes to an exponential curve $(n-L \ll n)$.

At very high temperatures when $\gamma \gg \beta L$, the whole decay is given

$$
I=\frac{\beta n_{0}^{2}}{\left(1+\beta n_{0} t\right)^{2}} \text {. }
$$

This corresponds to the "Obere Momentanzustand" of Lenard.

It can be seen from formulæ (8) and (1) that this occurs if

$$
T>\frac{E}{k} \quad \frac{1}{\ln s / \beta L},
$$

in our example if $T>400^{\circ} \mathrm{K}$.

At room temperature no phosphorescence will be observed if

In our example this would have occurred for trap depths less than

Fuller details will be published elsewhere.

We wish to thank Mr. van Moll and the directors of Philips Lamps, Ltd., for permission to publish this work.

$$
\text { H. A. Kuasens }
$$

Material Research Laboratory,

$$
\begin{aligned}
& \text { Philips Lamps, Ltd., } \\
& \text { New Road, } \\
& \text { Mitcham .Tunction, } \\
& \text { Surrey. }
\end{aligned}
$$

${ }^{1}$ Randall, J. T., and Wilkins, M. H. F., Proc. Roy. Soc., A., 184, 366

${ }^{2}$ Randall, J. T., and Wilkins, M. H. F., Proc. Roy. Soc., A, 184, 390 $(1945)$.

Mott, N. F., and Gurney, R. W., “Flectronic Processes", 135 (1940).

4 de Groot, W., Physica, 6, 275 (1939)

s Pringsheim, P., Trans. Faraday Soc., 35, 87 (1939).

\section{Diffraction of Light by Ultra-sonic Waves of Very High Frequencies}

UsING a specially constructed rectifler giving 1,100 volts and a Taylor $T 55$ valve with amphenol bases and special inductances, frequencies up to 100 megacycles per second have been produced. A tourmaline plate prepared in this laboratory with a thickness of $2 \mathrm{~mm}$. and a fundamental of about $2 \mathrm{Mc}$./sec. is made to oscillate up to its 54th harmonic, and at all stages it could be employed to maintain stationary waves in a column of water in the usual manner. Diffraction patterns at almost all the frequencies in the range 2 to $100 \mathrm{Mc}$./sec. could be observed. The highest frequency so far adopted" for such work is only $52 \cdot 5 \mathrm{Mc}$./sec. In order to detect dispersion, if any, of ultra-sonic velocity in water, the crystal has been simultaneously excited by us at two frequencies and both patterns photographed on

the same plate at the same instant.
Frequency measurement has been effected by beating the oscillator with a standard Philips heterodyne wave-meter, using an audio amplifier for hearing the beat note. Results for two frequencies are given below, the temperature of water at the time of the experiment being $32 \cdot 6^{\circ} \mathrm{C}$.

\begin{tabular}{|c|c|c|c|c|}
\hline $\begin{array}{c}\text { Order of } \\
\text { harmonic }\end{array}$ & $\begin{array}{c}\text { Frequency in } \\
\text { megacycles } \\
\text { per second }\end{array}$ & $\begin{array}{c}d \\
\text { Fringe width } \\
\text { in cm. }\end{array}$ & $v / d$ & $\begin{array}{c}\text { Velocity } \\
\text { calculated in } \\
\text { metres per } \\
\text { second }\end{array}$ \\
\hline 5 & $\begin{array}{c}9 \cdot 465 \\
92 \cdot 28\end{array}$ & $\begin{array}{l}0 \cdot 3655 \\
3 \cdot 569\end{array}$ & $\begin{array}{c}25 \cdot 89 \\
25 \cdot 86\end{array}$ & $\begin{array}{c}1526 \\
1524\end{array}$ \\
\hline
\end{tabular}

Results may be taken as indicating that there is no dispersion of ultra-sonic velocity in distilled water. Bar's values when extrapolated to $32 \cdot 6^{\circ} \mathrm{C}$. give a velocity of 1,523 metres per second.

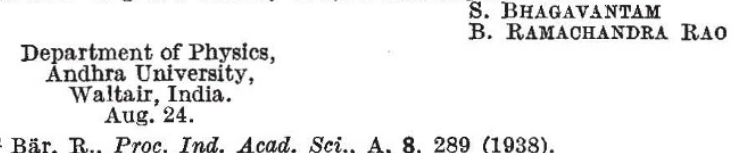

\section{Symbiotic Aspects of Nitrification}

IN an interesting article on the symbiosis between myxobacteria and nitrifying bacteria, Imsenecki ${ }^{1}$ describes an observation which he made during his studies on the biology of myxobacteria, when he was able to isolate from a culture of Nitrosomonas, grown in its elective medium, a heterotrophic organism which he has named Sorangium symbioticum. He postulates a symbiotic existence for these two organisms, suggesting that the development of the nitrifying bacteria precedes that of the myxobacteria, and that these chemotrophic nitriflers synthesize the organic material needed for the heterotrophic organisms, afterwards making this available by the autolysis of the Nitrosomonas cells. Unfortunately no quantitative data have been published.

Since the question of the metabolism of the nitrifying bacteria has evoked considerable interest in recent years, it was thought worth while to record the observations made by me in an attempt to correlate the rather incompatible phenomena of nitriflcation by the classical organisms described by Winogradsky as it occurs in artiflcial cultures and in their natural environment. The possibilities that the nitrifying bacteria function in close association with the saprophytes of the soil, and that the nitrifying organisms are themselves heterotrophic in some stage of their lives were examined. It was shown ${ }^{2}$ that when Nitrosomonas was cultured in its elective medium in the presence of organisms well known to take part in the transformations of nitrogen in the soil, as B. megatherium, B. mycoides, Azotobacter chroococcum etc., there was always enhanced nitriflcation in presence of added organic matter. These results question the strictly autotrophic character of the organisms tacitly assumed by Winogradsky and rather rigidly demonstrated by other workers. We have thus to assume that in mixed cultures, as in soil and sewage, the necessary carbon dioxide is obtained from the normal respiration of the heterotrophic 